\title{
Some results of experimental research of low frequency gas dynamic pulsations in pipelines of compressor mounts
}

\author{
Andrey V. Vasilyev \\ Samara State Technical University, Samara, Russian Federation \\ E-mail: avassil62@mail.ru \\ Received 7 May 2021; received in revised form 1 June 2021; accepted 8 June 2021 \\ DOI https://doi.org/10.21595/vp.2021.22107 \\ Check for updates \\ Copyright (C) 2021 Andrey V. Vasilyev. This is an open access article distributed under the Creative Commons Attribution License, which \\ permits unrestricted use, distribution, and reproduction in any medium, provided the original work is properly cited.
}

\begin{abstract}
Experimental researches of characteristic of low frequency gas dynamic gas pressure pulsations and caused by it noise and vibration were carried out on experimental compressor mount and in real industrial conditions. Analysis of results of experimental researches was carried out. According to results of experimental researches for compressor mount both in laboratory and in industrial conditions the maximal values of gas pressure pulsations were observed on the main frequency of compressor operation. It was experimentally shown that gas pressure pulsations are making the main contribution into forming of low frequency sound and vibration of compressor mount.
\end{abstract}

Keywords: low frequency, pulsations, compressor, pipeline, noise, vibration, research.

\section{Introduction}

Noise and vibration impact may cause not only human health problems, but also damage of equipment operation, pipelines destruction, damage of the tightness of seals in industrial conditions, which may cause many negative sequences $[1-3,5,7]$. Serious problem is low frequency noise and vibration reduction [3-5, 7-9].

Pipeline system of compressor mounts may be considered as elastic construction from the elements of different stiffness: straight sections of pipes, turns, armature, connected units, small technological devices, means of fixing pipelines etc. Such system may be considered as made up of individual sections because in it always elements are present (device supports, compressor body etc.) the rigidity of which is infinitely great and therefore it may be subdivided to the independent sections dynamically isolated from each other. The features of pipeline oscillations of these sections are different: straight-line pipelines under the influence of disturbing forces are performing bending vibrations, while flat and spatial are performing bending, torsional and longitudinal oscillations.

It should be noted that for compressor mounts excitation of vibrations to a large extend is occurs due to pulsating nature of the gas flow in pipelines and of oscillations of compressor body and the foundation caused by variable forces from the moving parts (piston, valves, forces from residual imbalance of rotating parts etc.).

According to opinion of many authors $[2,6,7]$ low frequency gas dynamic pulsations of pressure and of velocity of gas flow in pipeline mains are often one of the main reasons of low frequency noise and vibration of compressor mounts. Value of amplitude of every harmonic component of pulsating gas flow is determined by pipeline system construction and dimensions, therefore during conducting measurements it should be taking into consideration peculiarities of construction of pipeline system and of kind of compressor mount.

In a meantime, it is important to give experimental confirmation of the assumption that gas pressure pulsations are making the main input to forming of low frequency noise and vibration of compressor mount.

Thus paper is devoted to experimental research of low frequency gas dynamic pressure pulsations in pipeline of compressor mount and caused by it noise and vibration in laboratory and 
industrial conditions.

\section{Experimental research of low frequency gas dynamic pressure pulsations in pipeline of compressor mount and caused by it noise and vibration in laboratory conditions}

Experimental research of characteristic of low-frequency gas dynamic pressure pulsations and caused by it noise and vibration were carried out by using of compressor mount installed in department of chemicals technology and industrial ecology of Samara State Technical University of Russia. The scheme of compressor mount is shown in Fig. 1. For measurements of gas dynamic pressure pulsations portable 4-40 channels analyzer of vibration, acoustic and tensor signals LMS SCADAS Mobile of production of "LMS International" company together with pulsations sensor of "PCB" company. For measurements of compressor noise and vibration sound level meter, vibration meter, spectrum analyzer ASSISTANT TOTAL was used.

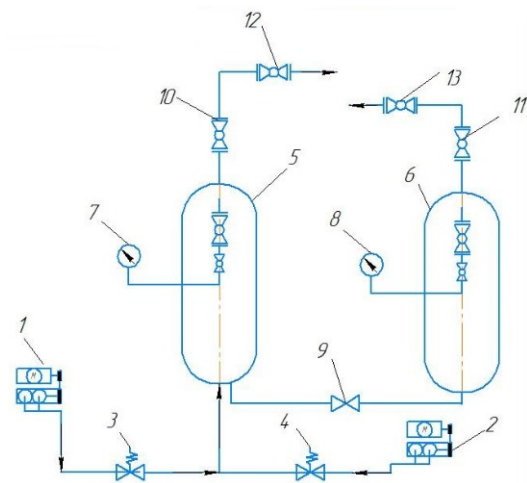

Fig. 1. The scheme of compressor mount for research of characteristic of low-frequency gas dynamic pressure pulsations: 1,2 - compressors, 3,4 - safety valves, 5,6 - receivers,

7,8 - pressure gauges, 9 - vent, 10,11,12, 13 - flanged connections

Main frequency of compressor operation is frequency $35 \mathrm{~Hz}$. Discharge pressure was fixed by pressure gauges. In Fig. 2 spectral characteristic of low-frequency gas pressure pulsations measured on experimental compressor mount during discharge pressure value 2 atmospheres is shown.

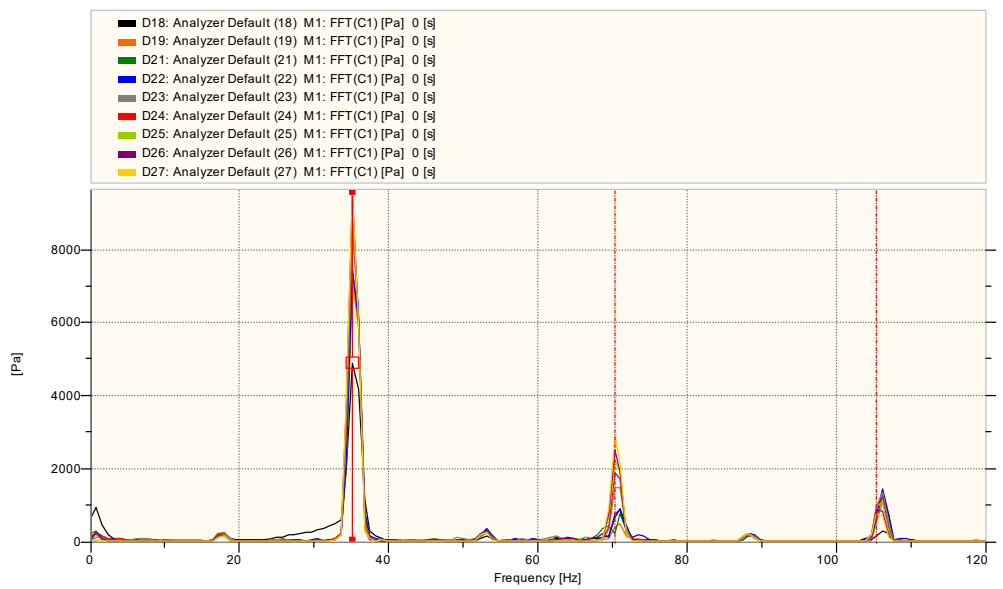

Fig. 2. Spectral characteristic of low-frequency gas dynamic pressure pulsations measured on experimental compressor mount during discharge pressure value 2 atmospheres 
Also measurements of noise and vibration levels were carried out on experimental compressor mount. In Fig. 3 third-octave spectrum of sound pressure level is shown. In Fig. 4 octave spectrum of vibration acceleration level on pipeline of experimental compressor mount (direction $X$ ) is shown.

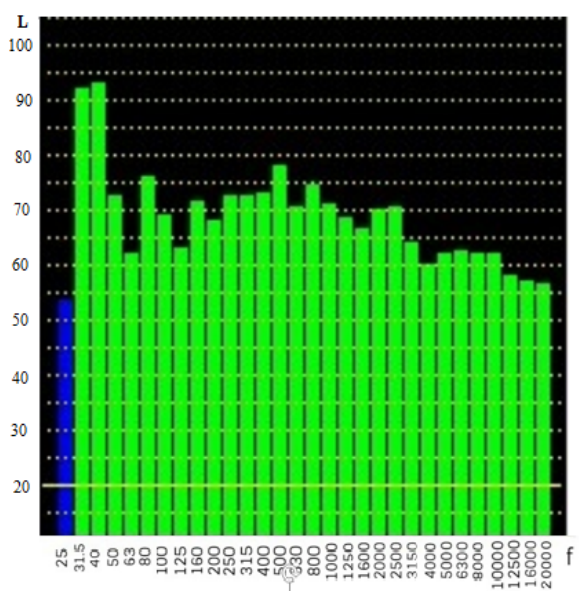

Fig. 3. Third-octave spectrum of sound pressure level Fig. 4. Octave spectrum of vibration acceleration measured on experimental compressor mount: vertical axis: sound pressure level $L, \mathrm{~dB}$; horizontal axis: frequency $f, \mathrm{~Hz}$

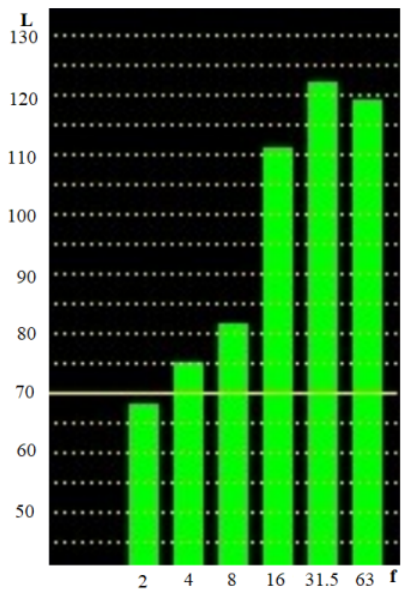
level on pipeline of experimental compressor mount (direction $X$ ): vertical axis: vibration acceleration level $L, \mathrm{~dB}$; horizontal axis: frequency $f, \mathrm{~Hz}$

Analysis of results of experimental researches was carried out. According to results of experimental researches it is possible to conclude that:

- The main frequency of compressor operation is $31,5 \mathrm{~Hz}$.

- For compressor mount for all measurements the maximal values of gas pressure pulsations were observed on the main frequency of compressor operation.

- Intensity of discrete components of gas pressure pulsations is depending on discharge pressure. The more high discharge pressure, the more amplitude of pulsations.

- The characteristic of pulsations is harmonic, amplitude of pulsations is increasing with increasing of discharge pressure.

- Analysis of octave and third octave spectra of vibration acceleration measured on pipeline of experimental compressor mount is showing that the maximal vibration levels are observed on the frequencies $31,5 \mathrm{~Hz}$ and $40 \mathrm{~Hz}$. The same results were obtained during the measurements of sound pressure level on the same experimental compressor mount.

Earlier during the experiments on the same mount it was achieved that the maximal values of low frequency gas pressure pulsations are observed on the frequency $35 \mathrm{~Hz}$. Thus, it was experimentally shown that gas pressure pulsations are making the main contribution into forming of low frequency sound and vibration of compressor mount.

\section{Experimental research of low frequency gas dynamic pressure pulsations in pipeline of compressor mount and caused by it noise and vibration in industrial conditions}

In real industrial conditions in chemical enterprise "KuibyshevAzot", Russia, acoustical and vibration characteristic of opposed piston compressor "Mannesmann - Meer" were done. General view of "Mannesmann - Meer" compressor mount in shop N4 of "KuibyshevAzot" public joint stock company is shown in Fig. 5. 


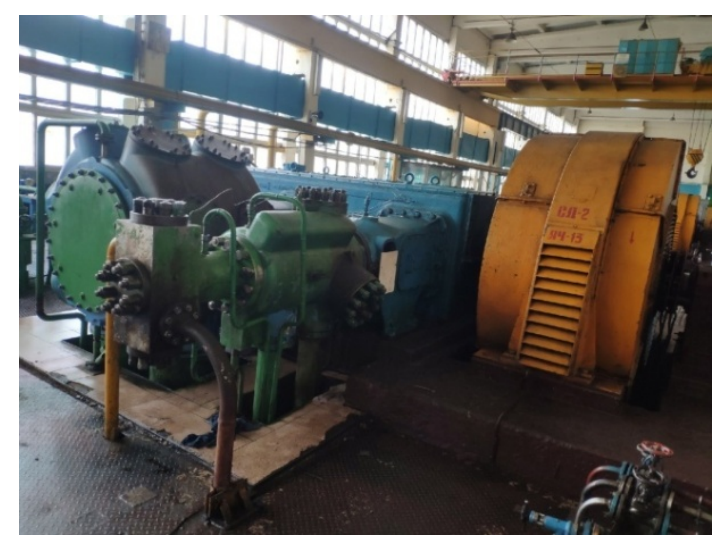

Fig. 5. General view of opposed compressor mount of in shop N4 of "KuibyshevAzot" public joint stock company

Analysis of results of experimental researches was carried out. According to results of experimental researches it is possible to conclude, that maximal values of sound pressure level were measured in low frequency range. On the main frequency of compressor operation $125 \mathrm{~Hz}$ sound pressure level is maximal which is in correspondence with measurement results on the laboratory compressor mount.

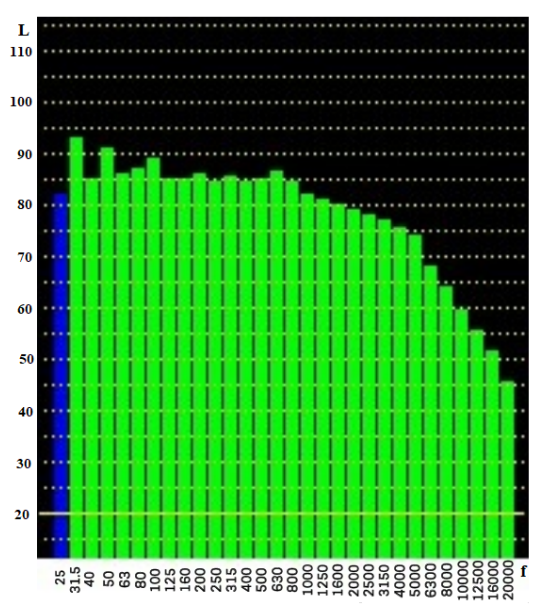

Fig. 6. Third-octave spectrum of sound pressure level measured during operation of opposed compressor mount of in shop N4 of "KuibyshevAzot" public joint stock company: vertical axis: sound pressure level $L, \mathrm{~dB}$; horizontal axis: frequency $f, \mathrm{~Hz}$

\section{Conclusions}

According to results of experimental researches of low frequency gas dynamic pressure pulsations in pipeline of compressor mount and caused by it noise and vibration in laboratory conditions it is possible to conclude that:

- For compressor mount for all measurements the maximal values of gas pressure pulsations were observed on the main frequency of compressor operation.

- Analysis of octave and third octave spectra of vibration acceleration measured on pipeline of experimental compressor mount is showing that the maximal vibration levels are observed on the frequencies $31,5 \mathrm{~Hz}$ and $40 \mathrm{~Hz}$. The same results were obtained during the measurements of sound pressure level on the same experimental compressor mount. Earlier during the experiments on the same mount it was achieved that the maximal values of low frequency gas pressure 
pulsations are observed on the frequency $35 \mathrm{~Hz}$. Thus, it was experimentally shown that gas pressure pulsations are making the main contribution into forming of low frequency sound and vibration of compressor mount.

According to results of experimental researches of acoustical characteristic of opposed piston compressor in real industrial conditions it is possible to conclude, that maximal values of sound pressure level were measured in low frequency range. On the main frequency of compressor operation $125 \mathrm{~Hz}$ sound pressure level is maximal.

The results of research will allow us develop efficient measures of reduction of low frequency gas pressure pulsations and caused by it noise and vibration of pipelines of compressor mounts. It may be reached in several ways: further development of efficient constructions of pressure pulsations dampers, active noise and vibration control devices, improvement of protection of compressor pipeline systems from vibration impact by using isolating mounts, monitoring of pulsations characteristic in compressor pipelines etc.

\section{Acknowledgement}

The author would like to express many thanks to Russian Scientific Foundation for financial supporting of research described in this paper by the grant, project number: 20-19-00222.

\section{References}

[1] Demidov I. V., Vaisberg L. A., Blekhman I. I. Vibrational dynamics of paramagnetic particles and processes of separation of granular materials. International Journal of Engineering Science, Vol. 141, 2019, p. 141-156.

[2] Musaakhunova L. F., Igolkin A. A., Shabanov K. Y. The vibroacoustic characteristics research of the gas pipeline. Procedia Engineering, Vol. 106, 2015, p. 316-324.

[3] Tupov V. B., Semin S. A., Evseev S. N., Kandybin V. P. Efficient reduction of noise from large industrial enterprise. Ecology of Industry, Vol. 8, 2016, p. 72-75.

[4] Van Der Berg G. P., Passchier Vermeer W. Assessment of low-frequency noise complaints. Proceedings of Inter-Noise 99 Congress, Lauderdale, FI, 1999, p. 1993-1999.

[5] Vasilyev A. V. Development and approbation of methods and technical solutions of reduction of vibration of power plants and joining mechanical systems. Procedia Engineering, Vol. 106, 2015, p. 354-362.

[6] Vasilyev A. V. Research of low-frequency gas pressure oscillations in duct systems of power plants using program provision. Journal Akustika, Czech Republic, Vol. 34, 2019, p. 123-126.

[7] Vasilyev A. V., Sannikov V. A., Tyurina N. V. Experience of estimation and reduction of noise and vibration of industrial enterprises of Russia. Journal Akustika, Vol. 32, 2019, p. 247-250.

[8] Zinkin V. M., Soldatov S. K., Bogomolov A. V., Dragan S. P. Relevant problems of protection of population from low frequency noise and infrasound. Technologies of Civil Security, Vol. 12, Issues 1-43, 2015, p. 90-96.

[9] Yakimovich A. V., Vasilyev A. V., Vasilyev V. A. Methods and results of monitoring of acoustical pollutions of urban territories on the example of Samara region of Russia. Ecology and Industry of Russia, Moscow, Vol. 23, Issue 6, 2019, p. 28-33. 